\title{
The Effects of Workforce Diversity on Employee Performance in Ethiopia: A Case of Addis Ababa Science and Technology University
}

\author{
Zelalem Daniel Ayano \\ Department of Industrial Management, Collage of natural and social sciences \\ Addis Ababa Science and Technology University, P.O. Box: 16417Addis Ababa, Ethiopia
}

\begin{abstract}
This research provides the link between differing types of diversity and employee Performance. Different variables were chosen subsequently reading the literature review. The aim of handling this research was to see the link between Diversity and employee Performance. By means of the use of questionnaires the primary data were acquired. Furthermore, the published documents were used as a secondary data source. The investigation was done by distributing 298 questionnaires to the academic and administrative staffs of Addis Ababa Science and Technology University (AASTU). They were administered personally and online. The collected data was analyzed to produce quantitative data, by applying SPSS version 20 and MS excel. Results show that there's a significant effects of the independent variables on employee performance after completely different workforce functioning within the university.
\end{abstract}

Keywords: Diversity Gender Diversity, Age Diversity, Ethnicity Diversity, Education Diversity, Workforce Diversity, Employee performance.

DOI: $10.7176 / \mathrm{EJBM} / 12-34-02$

Publication date: December $31^{\text {st }} 2020$

\section{Introduction}

The progress of technology and also the effort of world economy created the globe nearer than before. This action leads totally different entities like business, educational systems and different are exploration ways that to higher serve their constituents (Childs 2005).

According to (Jackson et al. 1995) diversity will be outlined because the presence of variations among members of a unit. Diversity is extremely necessary think about institutional life as organizations, as a result of the world becomes lots of various in terms of the gender, race, ethnicity, age, national origin and different personal characteristics of their members (Shaw and Barrett-Power 1998). Today, the workforce created up from peoples who are completely different and share different attitudes, needs, desires, values and work behaviors (Deluca and McDowell 1992). In present, because of economic process, migration and different cultural and social factors organizations are getting a lot of distributed age, ethnicity, ancestry, gender, physical abilities/qualities, race, educational background, geographic location, income, legal status, military expertise, non-secular beliefs, parental standing, and work expertise are the vital component of workforce diversity, however don't seem to be restricted by those (Hafiza and Faiza 2015).

Diversity is any facet that shows a distinction between one individual from the opposite one that features age, ethnicity, gender, education, work style, race (Noe, 2010). Within the same manner (Kreitz 2007) explains that diversity are often expressed as any noticeable deviation that differentiate one person to from the opposite that describes a large vary of hidden and un hidden qualities.

Gender-based inequities in organizations are strengthened and even by stereotypes and biases that describe positive characteristics and so the next standing to the males (Leonard and Levine 2003). In alternative words, organizations favor to rent males employees compared with girls as a result of they're appeared to have better performance and talent to manage their jobs. Besides, according to (Brown, 2008), important quantity of force diversity remains ineffective if gender problems don't seem to be initial recognized and managed.

Growing age diversity has become a part of several organizations (Kunze et al. 2009). There two major theories that illustrate a case for this relationship; the social identity and self-categorization. People are steered to classify themselves into bound teams on the idea of dimensions that are in person relevant for them in line with social identity and self-categorization theory (Kunze, et al. 2009).

According to (Dahlin et al. 2005) study some levels of diversity in ethnicity may well be positive related to innovation, high degree of diversity in ethnicity may well be negative since it will produce conflict and cliques according to social categorization.

Tracy and Sappington (1993) found that employers ordinarily reject using workers whose tuition, experience, or education is judged to be inadequate. On the opposite hand, this meant that education background is very important to workers. Workers cannot realize employment and perform well while not adequate education background. 


\section{$>$ Problem Statement}

The researches that were in serious trouble decades within the area of results of diversity at intervals groups indicates that diversity will have each negative and positive effect (Kochan et al. 2002).

In case of Ethiopia, as per the priority of the research worker, it's tough to mention that there's inadequate studies were undertaken within the area of the effect of workforce diversity on employee performance particularly within the education sector, specifically in Addis Ababa.

\section{$>$ Objective of the Study}

The purpose of this study is to examine The Effect of Workforce Diversity Towards Employee Performance in Ethiopia. The specific objectives of this study were to: evaluate the significance of workforce diversity over employee performance and to explore which diversity indicators (Age, ethnicity, gender and education background) has greater influence on employee performance in Ethiopia.

\section{Research Question}

1. Do Workforce diversity and employee performance have relationship in AASTU?

2. Which source of diversity indicators has a greater influence over employee performance?

\section{$>$ Scope of the Study}

The scope of the research is to assess The Effect of Workforce Diversity Towards Employee Performance In Ethiopia, A Case of Addis Ababa Science and Technology University; the study limited itself to the following workplace diversity dimensions; the chosen variables are Age diversity, ethnicity diversity, gender diversity and education background diversity; these all are independent Variables and employee performance is the dependent Variable. This research covers the one the university which is in Addis Ababa, Ethiopia. It can help universities, employees, managers as well Students of the sector. The analysis additionally shows that how different workforce diversity variables affect the employee performance.

\section{$>$ Significance of Study}

The study sought to examine The Effect of Workforce Diversity Towards Employee Performance In Ethiopia, A Case of Addis Ababa Science and Technology University. Hence, the University administrator and employees can make use of this research output. The output of the study can be used as a benchmark for the organizations officials as well as a source of methodological approach for studies dealing with diversified work force in general and diversified work force performance effectiveness in particular.

\section{$>$ Research Gap}

This study fills the gap of different research studies that have been conducted previously; after reviewing of different journals the outcomes of those studies shows that there it has an impact on the performance when diverse workforce is working in the education sector. In this research, one of such gaps was especially captured by the researcher is that most of that documents indicates that there is a shortage available empirical researches which are undertaken to know the effect of workforce diversity in the public higher education sector, especially in Addis Ababa.

\section{Literature review}

\subsection{Theoretical review}

\section{$>$ Blau's Theory of heterogeneousness}

Blau (1977) argue in his theory of heterogeneousness that companies with completely different levels of cultural diversity expertise unlike forces at work and organizational outcomes. Inside culturally same teams, members can tend to speak with each other a lot of usually and during a larger kind of ways in which leading to in-group attachments and shared perceptions. This boost cluster cohesion and future organizational end results. A very important however unheeded topic of study within the analysis on cluster or group diversity is that the basis for work cluster formation. According to (Blau, 1977), several organizational teams, like practical departments, is also experiencing larger gender and culture diversity because the increasing diversity of the workforce brings a lot of diverse set of employees to organizations. However, the flow of diverse employees doesn't essentially mean that everyone organizational teams can assemble during a numerous means. Blau's, (1977) discussion of cluster heterogeneousness and structure is also instructive. On the one hand, Blau's, (1977) asserts that similarities on one nominal parameter (e.g., race) can promote social associations. On the opposite hand, he maintains that individuals can associate not solely with members of their own teams however conjointly with members of alternative teams.

\section{$>$ Employees performance}

Byrnes (1984) outlined performance as working operating effective that is the approach within which someone will does a job, judged by its effectiveness. It's how well associate worker is fulfilling the necessities of employment (Rue and Byars 1993). Smith (2010) argued that smart workforce diversity practices within the space of human resources are believed to boost worker and organizational performance. In line with (Cornelius 2001), effective performance will be a key determinant within the action of business objectives whereas maximizing the contribution of workers. Schuler (1992), determined that a performance appraisal system ought to be objective, relevant to the work and also the organization, honest to all or any workers and offers no special treatment. 


\section{$>$ Gender}

Current studies recognized that gender discrimination will have an effect on staff performance. Genders are outlined as a variety of variations between man and girls, extending from a biological to the social. Abbas et al. (2010) propose that there are 3 dimension of gender discrimination; gender discrimination in hiring, gender discrimination in promotion and gender discrimination in provision of products and facilities. According to (Abbas et al., 2010), girls don't have a favorable position once it involves hiring compared with men. There's additionally girls discrimination in supervisor regular payment or obtaining promotion. Women supervisor who replace male superintendent gets a lower regular payment level. Additionally to that, it shows that gender discrimination effects employee's performance additionally as organizations productivity.

\section{$>$ Age}

\section{Social Identity and Self Categorization}

Possible explanations for negative effects age diversity is derived from the idea of structural demography, which attracts heavily on theories of social identity and self-categorization. This theory suggests that people tend to classify themselves and other into sure teams on the idea of dimensions that are in person relevant for them. These dimensions usually embrace demographic classes like gender, age, or ethnicity (Kunze et al. 2009). According to social identity theory, social identity and intergroup behavior are lead by the pursuit of critical positive social identity; through positive intergroup distinctiveness, that successively, is impelled by the requirement for positive vanity (Hogg and Terry 2000). Additionally to being impelled by self-enhancement, social identity processes are impelled by a necessity to cut back subjective uncertainty concerning one's perceptions, attitudes, feelings, and behaviors and, ultimately, one's self-concept and place among the social world. As in keeping with (Al Jishi 2009), the extent of performance depends on the extent of motivation that stimulates somebody to figure and do the mandatory tasks to attain the goals.

\section{$>$ Ethnicity}

The growth of a diversified cultural workforce was the main focus of the 90 s and is gaining a lot of momentum into the new era (Watson 2002). Together with the rise in diversity has been a rise within the use of labor groups normally, with intention of utilizing bigger participation and activity to boost and increase each worker satisfaction and business performance. Although the character of workforce composition is quickly changing into a lot of mixed in terms of gender, age, ethnicity and parallel interest has been increasing concerning the impact of such diversity in our academic institutions (Watson 2002). The diversified cultural increase in businesses is thanks to diversified cultural increase of our society and, thus, conjointly pervades familial, educational, and spiritual circles. In line with (Watson 2002), the variations in cultural characteristics were prognosticative of team scores, which might be taken because the advantage of getting ethnically completely different views for team problem solving resulted in enhanced team performance once the groups learned a way to utilize these variations to their profit.

\section{$>$ Educational Background}

According to (Maingi 2015) organizational managers implement educational diversity initiatives in efforts to stimulate and encourage every individual to figure effectively with others in order that organizational goals are attained. A person's academic background will be a major indicator of their knowledge, skills, and capability. Moreover, the selection of a particular academic major might mirror one's psychological feature strength and temperament. For instance, a person studies in computer science will be expected to own a somewhat completely different psychological feature disposition than a person studies in selling or advertising. As in purposeful experience, difference in academic background looks to own a positive impact on team performance as a result of it fosters a broader vary of psychological feature skills. Contend that the assimilative capability of the organization is probably going to extend with diversity in knowledge structures as mirrored in numerous academic levels (Maingi J. W., 2015).

\subsection{Conceptual Review Proposed Conceptual Framework}

From the journals, researcher understands that the two variables of workforce diversity are vital in affecting worker performance. Thus the researcher tends to came out with a framework as declared below. The study consists Independent variables Age diversity, ethnicity diversity, gender diversity and education background diversity, and the dependent variable is employee performance. These relationships are illustrated in Figure 1 . Below 
Independent variable

Dependent variable

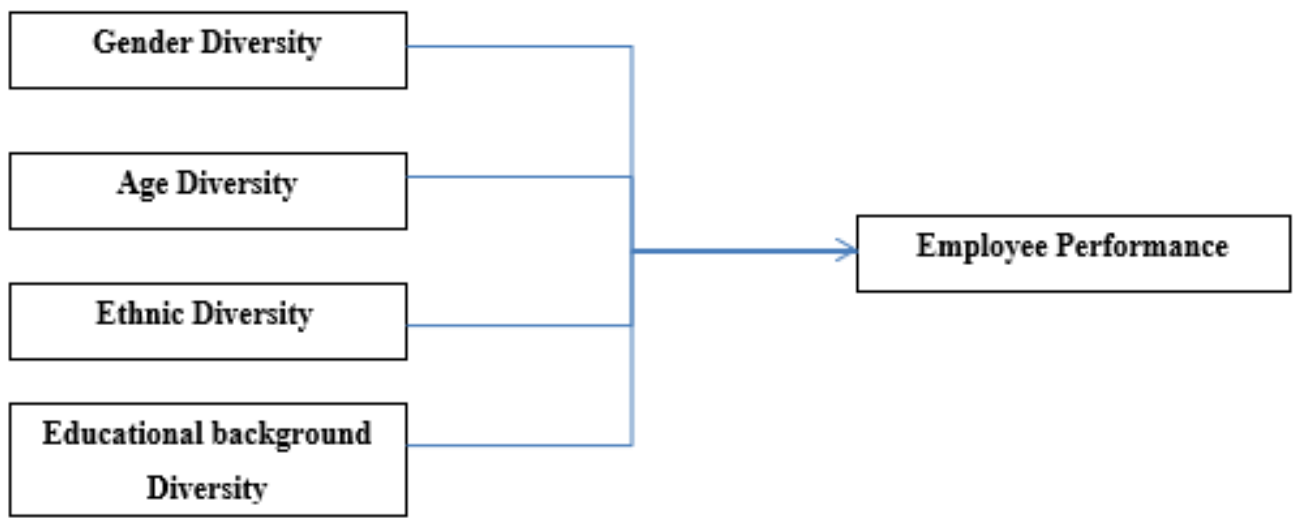

Figure 2; Conceptual Framework

To fulfill organizational goals, every team should be effective in terms of its internal functioning. Additionally, every team should effectively manage its relationships with different groups and people within the organization. Through their relationships, team members could gain access to required resources and exert influence that's helpful to the team and its individual members (West et al. 2003).

\subsection{Hypothesis development}

Gender Diversity

$\mathrm{H}_{0}$ : There is no significant relationship between gender and employee performance

$\mathrm{H}_{1}$ : There is significant relationship between gender and employee performance

$>$ Age Diversity

$\mathrm{H}_{0:}$ There is no significant relationship between age diversity and employee performance

$\mathrm{H}_{1}$ : There is a significant relationship between age diversity and employee performance

\section{$>$ Ethnic Diversity}

$\mathrm{H}_{0}$ : There is no significant relationship between ethnic and employee performance

$\mathrm{H}_{1}$ : There is significant relationship between ethnic and employee performance Research Methodology

\section{$>$ Education background}

$\mathrm{H}_{0}$ : There is no significant relationship between education background and employee performance

$\mathrm{H}_{1}$ : There is significant relationship between education background and employee performance

\section{Research methodology}

Research project needs the foremost appropriate techniques or ways to come back out with associate degree of correct result. To complete this analysis, methodologies are developed to refine the study that allows the research worker to engender the information needed.

\section{$>$ Research Design and data collection}

Research design is that the overall arrangement or strategy for conducting or concluding the analysis (Oso \& Onen 2008). Explanatory survey study and quantitative business research are used. During this analysis primary data were collected by questionnaire survey it was by hand administering as well administered via internet and secondary sources of data were from published journal articles, books, publications, websites etc. are going to be used as applicable for the data collection.

\section{$>$ Target Population}

Population refers to the whole cluster of individuals, events, or things that the research worker desires to analyze (Sekaran and Bougie 2003). The targeted company is Addis Ababa Science and Technology University. Therefore, the target population for this research will be the employees in organization academic and administrative staffs. Which consists of 760 and 573 respectively. Generally, the population of the study is 1333 .

\section{$>$ Sample Size Determination}

The study draws sample from all employees of the each staffs of the university, the sample and the formula below used to calculate sample size, according to (kothari 2004) which gave a sample size of 298 responses.

\section{$>$ Response Rate}

Generally, 298 questionnaires were distributed to sample respondents based on the sample size the study. Only 211 questionnaires were returned from the respondents. However the research attained a total response rate of $70.80 \%$ which believe to be encouraging.

\section{$>$ Reliability Test Results}

After preparing the questionnaire, reliability analysis were done to confirm measurements reliability for the research. Reliability of the questionnaires were tested also. Using reliability test with the assistance of Statistical 
Package for Social Science (SPSS) software. The results of pilot test is shown below:

Table 1. Reliability Test

\begin{tabular}{rlll}
\hline № & Constructs & Cronbach's Alpha & № of Items \\
\hline 1. & Gender & 0.790 & 9 \\
2. & Age & 0.720 & 4 \\
3. & Ethnicity & 0.781 & 6 \\
4. & Education background & 0.714 & 6 \\
5. & Employee performance & 0.793 & 10 \\
\hline
\end{tabular}

Source: Data generated by SPSS version 20

\subsection{Methods of data analysis}

\section{$>$ Inferential Analysis}

Inferential statistics permits to draw conclusions from sample data which may not be right away obvious to the totality of the population. Inferential statistics use a random sample of data taken from a population to explain and build inferences concerning the population. Inferential statistics are valuable once it's not convenient or doable to look at every member of a whole population. This study also uses;

I. The correlation analysis,

II. Multiple linear regression analysis, and

III. One-way analysis of variance (ANOVA).

ANOVA was also applied to check the hypotheses whether it absolutely was accepted or rejected. Regression and correlation analysis were applied to investigate the information. Regression analysis was applied to test and estimate the association and link between variables. Correlation analysis was applied to search out the link between variables in magnitude i.e. estimating relationship in terms of amount.

\section{Results and discussions}

\subsection{Correlation Analysis}

Table 2. Relationship between workforce diversity and employee performance

\begin{tabular}{|c|c|c|c|c|}
\hline \multicolumn{5}{|l|}{ Correlations } \\
\hline & Gender & Age Diversity & Ethnicity & Educational \\
\hline & Diversity & & Diversity & Background \\
\hline & & & & Diversity \\
\hline \multirow{2}{*}{ Gender Diversity } & Pearson Correlation 1 & $.581^{* *}$ & $.540^{* *}$ & $.457^{* *}$ \\
\hline & Sig. (2-tailed) & .000 & .000 & .000 \\
\hline \multirow{2}{*}{ Age Diversity } & Pearson Correlation $.581^{* *}$ & 1 & $.519^{* *}$ & $.366^{* *}$ \\
\hline & Sig. (2-tailed) $\quad .000$ & & .000 & .000 \\
\hline \multirow{2}{*}{ Ethnicity Diversity } & Pearson Correlation $.540^{* *}$ & $.519^{* *}$ & 1 & $.526^{* *}$ \\
\hline & Sig. (2-tailed) $\quad .000$ & .000 & & .000 \\
\hline Educational & Pearson Correlation $.457^{* *}$ & $.366^{* *}$ & $.526^{* *}$ & 1 \\
\hline \multirow{3}{*}{$\begin{array}{l}\text { Background Diversity } \\
\text { Employee } \\
\text { Performance }\end{array}$} & Sig. (2-tailed) $\quad .000$ & .000 & .000 & \\
\hline & Pearson Correlation $.514^{* *}$ & $.358^{* *}$ & $.516^{* *}$ & $.574^{* *}$ \\
\hline & $\begin{array}{ll}\text { Sig. (2-tailed) } & .000\end{array}$ & .000 & .000 & .000 \\
\hline
\end{tabular}

Source: Data generated by SPSS version 20

\section{Interpretation of correlation of employee performance and gender diversity}

There is positive relationship between gender group and employee performance because of the value for correlation coefficient is positive. The gender group variable has a 0.514 correlation with the employee performance variable.

$>$ Interpretation of correlation of employee performance and age diversity

There is positive significant relationship between age group and employee performance because of the value for correlation coefficient is positive. The age group variable has a 0.358 correlation with the employee performance variable

$>$.Interpretation of correlation of employee performance and ethnicity diversity

There is positive relationship between ethnicity group and employee performance because of the value for correlation coefficient is positive. The ethnicity group variable has a 0.516 correlation with the employee performance variable.

\section{$>$ Interpretation of correlation of employee performance and education background diversity}

There is positive relationship between education background group and employee performance because of the value for correlation coefficient is positive. The education background group variable has a 0.574 correlation with the employee performance variable. 


\subsection{Analysis of Variance (ANOVA)}

Table 3. Analysis of Variance (ANOVA ${ }^{a}$ )

\begin{tabular}{llrrrrr}
\hline Model & & Sum of Squares & df & Mean Square & F & \multicolumn{1}{c}{ Sig. } \\
\hline & Regression & 31.026 & 4 & 7.757 & 39.327 & $.000^{\mathrm{b}}$ \\
Residual & 40.629 & 206 & .197 & & \\
& Total & 71.655 & 210 & & & \\
\hline
\end{tabular}

Source: Data generated by SPSS version 20

Interpretation of correlation of the Analysis of Variance (ANOVA) result

From the above ANOVA statistics in Table 3, the study established the regression model had a significance level of 0.000 which is an indication that the data was ideal for making a conclusion on the population parameters as the value of significance ( $\mathrm{p}$-value) was less than 0.05 or $5 \%$. Besides that, the F-statistic is significant at the value of 39.327. Therefore, the model is a good descriptor of the relation between the dependent and predictor variables. This indicates that Age Diversity, Educational Diversity, Ethnic Diversity, and Gender Diversity all are affect employee performance. The significance value was less than 0.05 indicating that the model was significant. Null hypothesis (H0) is not accepted but alternative hypothesis (H1) is accepted.

\subsection{Multiple Regression Analysis}

Table 4. Model Summary

\begin{tabular}{|c|c|c|c|c|}
\hline Model & $\mathrm{R}$ & R Square & Adjusted R Square & Std. Error of the Estimate \\
\hline & $.658^{\mathrm{a}}$ & .433 & .422 & .44411 \\
\hline
\end{tabular}

The value of adjusted $\mathrm{R}$ squared as a measure of model fitted by the significant variables was 0.422 an indication that there was variation of 42.2 percent on employee performance due to changes in Gender, Age, Ethnic and Educational Diversity at 95 percent confidence interval. This shows that 42.2 percent changes in employee performance in Addis Ababa Science and Technology University (AASTU) could be accounted to Gender, Age, Ethnic and Educational Diversity. $\mathrm{R}$ is the correlation coefficient which shows the relationship between the study variables, from the findings shown in the Table 4 is notable that there exists moderate positive relationship between the study variables as shown by 0.658 . Besides that, the coefficient of determination ( $\mathrm{R}$ square) can help us in explaining variance. The $\mathrm{R}$ square figure of the four independent variables is 0.433 . These also mean that independent variables (Educational Diversity, Age Diversity, Ethnic Diversity, and Gender Diversity) can explain $43.3 \%$ of the variation in dependent variable (employee performance). However, it is still leaves $56.7 \%(100 \%-$ $43.3 \%$ ) unexplained in this research. In other words, there are other additional variables that are important in explaining employee performance that have not been considered in this research

The following table 5 shows the regression coefficients of the independent variables (diversity predictors). Table 5. Regression Coefficients

\begin{tabular}{|c|c|c|c|c|c|c|c|c|}
\hline \multirow{2}{*}{\multicolumn{2}{|c|}{ Model }} & \multicolumn{2}{|c|}{$\begin{array}{c}\text { Unstandardized } \\
\text { Coefficients }\end{array}$} & \multirow{2}{*}{$\begin{array}{c}\text { Standardized } \\
\text { Coefficients } \\
\text { Beta }\end{array}$} & \multirow[t]{2}{*}{$\mathrm{t}$} & \multirow[t]{2}{*}{ Sig. } & \multicolumn{2}{|c|}{$\begin{array}{c}\text { Collinearity } \\
\text { Statistics }\end{array}$} \\
\hline & & $\mathrm{B}$ & Std. Error & & & & Tolerance & VIF \\
\hline \multirow{5}{*}{1} & (Constant) & 1.339 & .196 & & 6.821 & .000 & & \\
\hline & Gender Diversity & .231 & .064 & .256 & 3.642 & .000 & .559 & 1.789 \\
\hline & Age Diversity & -.021 & .050 & -.028 & -.417 & .677 & .603 & 1.660 \\
\hline & Ethnicity Diversity & .168 & .058 & .203 & 2.908 & .004 & .565 & 1.769 \\
\hline & $\begin{array}{l}\text { Educational } \\
\text { Background Divers }\end{array}$ & .292 & .051 & .361 & 5.672 & .000 & .680 & 1.470 \\
\hline
\end{tabular}

Source: Data generated by SPSS version 20

The findings revealed that gender diversity, age diversity, ethnic diversity and educational diversity to a constant zero, employee performance in Addis Ababa Science and Technology University (AASTU) would be at 1.339 , at one percent change in gender diversity would lead to increase employee performance in Addis Ababa Science and Technology University (AASTU) by a variations of $0.231 \%$, at a one year increase in age diversity would decrease employee performance in Addis Ababa Science and Technology University (AASTU) by a variations of $-0.021 \%$, at one percent increase in ethnicity diversity would increase employee performance in Addis Ababa Science and Technology University (AASTU) by a variations of $0.168 \%$ and at one percent change in educational diversity would increase employee performance in Addis Ababa Science and Technology University (AASTU) by a variations of $0.292 \%$.

Further, the study established that both the variables gender diversity, ethnic diversity and educational diversity were significant as their significant value was less than $(p<0.05)$ but not age diversity since its $p$-value is greater than 0.05 . At $5 \%$ level of significance, gender diversity had a p-value of 0.000 , ethnic diversity had a $p$ value of 0.004 , and educational background diversity had a p-value of 0.000 . Age diversity had a p-value of 0.677 . 
Therefore, the most significant factor is Educational Background.

Finally, from the data in Table 5, the study established the fitted regression equation:

Where,

$$
\mathrm{Y}=\beta_{0}+\beta_{1} \mathrm{X}_{1}+\beta_{2} \mathrm{X}_{2}+, \ldots+\beta_{\mathrm{K}} \mathrm{X}_{\mathrm{K}}
$$

$\mathrm{Y}$ is the dependent variable

$\beta 0$ is the regression constant

$\mathrm{Xi}$ 's $\left(\mathrm{X}_{1}, \mathrm{X}_{2}, \ldots, \mathrm{X}_{\mathrm{K}}\right)$ are explanatory or independent variables

$\beta i$ 's $\left(\beta_{1}, \beta_{2}, \ldots, \beta_{\mathrm{K}}\right)$ are regression coefficients

$\varepsilon$ is the random disturbance term

$$
\mathbf{Y}=1.339+0.231 \mathrm{X}_{1}-0.021 \mathrm{X}_{2}+0.168 \mathrm{X}_{3}+0.292 \mathrm{X}_{4+\varepsilon}
$$

Therefore,

Employee performance in Addis Ababa Science and Technology University $($ AASTU) $=1.339+(0.231)$ Gender Diversity - (0.021) Age Diversity $+(0.168)$ Ethnic Diversity $+(0.292)$ Educational diversity.

From the results of this study, Educational Background diversity contributed more to the Employee performance in Addis Ababa Science and Technology University (AASTU).

Table 6. Ranking of Independent Variables based on Standardized Coefficient, Beta

\begin{tabular}{llc}
\hline Independent Variables & $\begin{array}{l}\text { Standardized } \\
\text { Coefficients, Beta }\end{array}$ & Ranking \\
\hline Education background group & 0.361 & 1. \\
Gender group & 0.256 & 2. \\
Ethnicity group & 0.203 & 3. \\
Age group & -0.028 & 4. \\
\hline
\end{tabular}

Source: Data generated by SPSS version 20

From the Coefficient's table, educational background group is the first and most significant independent variable in this research since its t-value is 5.672 and $p$-value is 0.000 , which is lower than alpha value 0.01 . This also shows that educational background is significant to predict perceived employee performance. Besides that, educational background group is the predictor variable that contribute the highest to the variation of the perceived employee performance because Beta value (under standardized coefficients) for this predictor variable is the largest (0.361) if compare to other predictor variables (gender, age, and ethnicity).

Besides, Gender group is second most significant independent variable where it carries out the t-value 3.642 and the p-value 0.000 , which is lower than the alpha value 0.01 . This shows that gender group is significant to predict perceived employee performance. In addition, gender group contribute the second highest to the variation of the perceived employee performance because Beta value (under standardized coefficients) for this predictor variable is the second largest $(0.256)$.

The third most significant independent variable is Ethnicity group, where the t-value is 2.908 and the p-value is 0.004 which is lower than the alpha value 0.01 . This represent that the ethnicity group is significant to predict perceived employability. Besides, Ethnicity group contribute the third highest to the variation of the perceived employee performance because Beta value (under standardized coefficients) for this predictor variable is the third largest (0.203).

Lastly, in this research, Age group is significant independent variable where it carries out the t-value -0.417 and the p-value 0.677 , which more than alpha value of 0.05 . This shows that age group is not significant to predict perceived employee performance. In addition, age group contributes Beta value (under standardized coefficients) for this predictor variable is $(-0.028)$.

\section{$>$ Interpretation of VIF}

Collinearity Statistics contains VIF which indicates multicollinearity between variables. Here, in this Research Study, all the VIF values are less than 10. If values are less than 10 it means there is no multicollinearity between variables.

VIF value of Gender Diversity is 1.789 which is less than 10. There is no multicollinearity between variables. VIF value of Age Diversity is 1.660 which is less than 10. There is no multicollinearity between variables. VIF value of Ethnicity Diversity is 1.029 which is less than 10 . There is no multicollinearity between variables.

VIF value of Educational Diversity is 1.470 which is less than 10 . There is no multicollinearity between variables.

\section{Conclusion and Recommendations for Future Study \\ $>$ Conclusion}

Based on the results showed, The Effects of Workforce Diversity (age and ethnicity) Towards Employee Performance in Addis Ababa Science and Technology University (AASTU) is significant in most of the ways. The 
research investigated the practice of workforce diversity consideration in AASTU in all levels of the diversities. In addition to that all of the independent variables (age and ethnicity) have a positive relation with the dependent variable (employee performance). As well as one of the diversity indicator ethnic diversity had a greater influence on the dependent variable over the rest. Therefore it is possible to say that the objectives of the research are achieved or fulfilled with the results acceptance. Since the workforce diversity is becomes one among preferred ways in which to gauge worker performance in organization in recent years, the analysis tends to stipulate the proof to support future researches associated with this field.

\section{$>$ Recommendations for Future Study}

This study will function as a suggestion for future researches. The researcher focus is on the gender, age, ethnicity, and education background of the employees and whether or not it'll have an effect on their performance in a corporation.

This research result's a comparison on the performance of the individual worker and but not comparison which supported team performance. Therefore the researcher tends to believe that future analysis will go deeper during this space.

Researchers ought to succeed agreement on how workforce diversity is read and to develop a usually accepted definition of workforce diversity, so permitting additional researches to require place to explore additional edges and implications of workforce diversity towards organizations performance.

\section{References}

Abbas, Q., Hameed, A., \& Waheed, A. (2010). Gender Discrimination \& Its Affect on Employee Performance/Productivity. Managerial and Entrepreneurial Developments in the Mediterranean Area.

Blau, P. M. (1977). Inequality and heterogeneity: A primitive theory of social structure (Vol. 7). New York: Free Press.

Brown, S. L. (2008). Diversity in the workplace: A study of gender, race, age, and salary level. Capella University Byrnes, J. F. (1984). Costing Human Resources: The Financial Impact of Behavior in Organizations.

Childs Jr, J. T. (2005). Managing workforce diversity at IBM: A global HR topic that has arrived. Human Resource Management, 44(1), 73-77.

Cornelius, N. (2001). Human resource management: A managerial perspective. Cengage Learning EMEA.

Dahlin, K. B., Weingart, L. R., \& Hinds, P. J. (2005). Team diversity and information use. Academy of management journal, 48(6), 1107-1123.

DeLuca, J. M., \& McDowell, R. N. (1992). Managing diversity: A strategic 'grass roots' approach. Diversity in the workplace: Human resources initiatives, 1

Hafiza, S. I., \& Faiza, M. S. (2015). Impact of workforce diversity on organizational performance in the education sector of Karachi Pakistan. International journal of scientific \& Engineering Research, 2(1), 10-15.

Hogg, M. A., \& Terry, D. I. (2000). Social identity and self-categorization processes in organizational contexts. Academy of management review, 25(1), 121-140.

Jackson, S. E., May, K. E., Whitney, K., Guzzo, R. A., \& Salas, E. (1995). Understanding the dynamics of diversity in decision-making teams. Team effectiveness and decision making in organizations, 204, 261.

Kochan, T., Bezrukova, K., Ely, R., Jackson, S., Joshi, A., Jehn, K., ... \& Thomas, D. (2002). The effects of diversity on business performance. Report of the Diversity Research Network, 2003, 42.

Kothari, C. R. (2004). Research methodology: Methods and techniques. New Age International.

Kreitz, P. A. (2008). Best practices for managing organizational diversity. The Journal of Academic Librarianship, 34(2), 101-120.

Kunze, F., Boehm, S., \& Bruch, H. (2009, August). Age diversity, age discrimination, and performance consequences--a cross organizational study. In Academy of Management Proceedings (Vol. 2009, No. 1, pp. 1-6). Briarcliff Manor, NY 10510: Academy of Management.

Leonard, J. S., \& Levine, D. I. (2003). Diversity, discrimination, and performance. Institute of Industrial Relations Working Paper No. iirwps-091-03.

Lewis, T. R., \& Sappington, D. E. (1993). Choosing workers' qualifications: No experience necessary?. International Economic Review, 479-502.

Maingi, J. W., \& Makori, M. (2015). Effect Of workforce diversity on employee performance in Kenya: A case of Kenya School of Government. Strategic Journal of Business \& Change Management, 2(2), 52-68.

Noe, A. (2010). Employee training and development. (5thed.). New York, NY: Mc-Graw Hill.

Oso, W., \& Onen, D. (2008). A general guide to writing research and report: A hand book for beginning research.

Rue, L. W., \& Byars, L. L. (1993). Supervision. Key Link to Productivity, Richard D. Irwin. Inc, Homewood, 111.

Schuler, R. S. (1992). Strategic human resources management: Linking the people with the strategic needs of the business. Organizational dynamics, $21(1), 18-32$.

Sekaran, U., \& Bougie, R. (2016). Research methods for business: A skill building approach. John Wiley \& Sons. Shaw, J. B., \& Barrett-Power, E. (1998). The effects of diversity on small work group processes and 
performance. Human Relations, 51(10), 1307-1325.

Smith, P. (2010). Increasing Productivity: Workforce Training and Development. The Bleaner.

Watson, W. E., Johnson, L., \& Zgourides, G. D. (2002). The influence of ethnic diversity on leadership, group process, and performance: An examination of learning teams. International Journal of Intercultural Relations, 26(1), 1-16.

West, D. T., Tjosvold, D., \& Smith, K. (2003). Managing workforce diversity to enhance cooperation in an organization. 